\title{
Fuzzy Approach for the Synthesis of Mass Exchange Network
}

\author{
Nesma Younes \\ Department of Chemical \\ Engineering \\ The British University in Egypt, \\ Cairo, Egypt
}

\author{
Said M. Abdallah \\ Department of Chemical and \\ Petrochemical Engineering, \\ Faculty of Petroleum and \\ Mining Engineering, Suez \\ University, Suez, Egypt
}

\author{
M. Abdel Alim \\ Department of Chemical and \\ Petrochemical Engineering, \\ Faculty of Petroleum and \\ Mining Engineering, Suez \\ University, Suez, Egypt
}

\begin{abstract}
This article addresses a fuzzy logic approach to calculate the optimum minimum allowable composition difference $(\varepsilon)$ to target the minimum total annualized cost (TAC) of a mass exchange network (MEN), which is based on combining composition interval diagram (CID) with fuzzy set theory. The value of $\varepsilon$ directly affect the TAC as a main constrain. By utilizing this decision algorithm it gives the opportunity to calculate the optimum composition difference by decision making from a wide range of assumed $\varepsilon$. This method is very simple and more convenient than the methods previously published; as the decision is taken without calculating TAC for every assumed $\varepsilon$.
\end{abstract}

\section{Keywords}

Mass exchange network, Fuzzy Approach, Mass Integration, Process synthesis, Process Optimization, Multi-objective decision making

\section{INTRODUCTION}

Absorption, stripping, extraction, leaching, adsorption, and ion exchange; all are the indispensable mass exchange operations used in chemical industries [7]. The purpose of mass-exchange networks (MENs) is to use mass (e.g., water) more efficiently, decreasing simultaneously the waste discharged to the environment and the raw material used and thus optimizing the cost of operation by minimizing treatment of waste cost and utility cost [8].

It is widely accepted that synthesis of mass exchange network is important in achieving minimum total annualized cost (TAC) for pollution prevention. The concept of synthesizing and integration of mass exchange networks (MENs) and the development of a systematic technique for their optimal design were introduced by [5]. In contrast to direct recycle of waste streams, mass integration involves the interception of such process streams with mass exchangers before recycling.

The aim of MEN synthesis is to synthesis a network of mass exchange units that can preferentially transfer certain species from rich streams (waste streams) to the mass separating agents (MSAs) (lean streams) at minimum venture cost. Figure (1) shows a schematic representation of a MEN system. There are several well developed methods for synthesizing of MEN. But the capital cost couldn't be considered in the network analysis or it is difficult to be considered in the synthesis process. The factors that affect the optimization of the MEN total cost; two of which depend on the minimum allowable $\varepsilon$ assumed when synthesizing the MEN; the amount of MSAs and number of stages.
It was observed that the cost of a MEN varied with $\varepsilon$ considerably. When $\varepsilon$ is increased, the operating cost would increase, whereas the capital cost would decrease, so the values of $\varepsilon$ should be taken as optimal variables and optimized to obtain a minimum TAC. They presented an automated synthesis procedure iteratively for a range of $\varepsilon$ values in an attempt to minimize the TAC of the network and the optimal $\varepsilon$ [2]. Papalexandri and his colleagues pointed out that the main limitation of the above procedure introduced by El-Halwagi and Manousiouthakis was its sequential approach [9]. In the design process, the operating and capital costs were not considered simultaneously. This might induce one to obtain a local optimal network. So they presented a hyper-structure model for MENs containing many structural alternatives, and avoided using the pinch division. But their design work met with three challenging factors [4].

First, the failure to incorporate certain configurations in the hyper-structure may result in suboptimal solutions. Second, the nonlinear properties of the mathematical formulation often make it difficult to locate the global optimum. Third, once the mathematical program is formulated, the engineer is essentially removed from the design process.

Decision-making problem is the process of finding the best option from all of the feasible alternatives. In almost all such problems the multiplicity of criteria for judging the alternatives is pervasive. That is, for many such problems, the decision maker wants to solve a multiple criteria decision making (MCDM) problem.

It is difficult to explain optimization techniques in a few words; there are plenty of books describing different methods and approaches. Generally, to optimize means selecting the best available option from a wide range of possible choices. This article considers $\varepsilon$ as a set of unequal variables for each equilibrium equation of a rich-lean stream pair, employing them to build the composition interval diagram (CID). Kremser's equation is used to size each mass exchanger [6], and the optimal problem is solved by the fuzzy approach method. This method considers the capital cost and operating cost simultaneously with the TAC as an objective to obtain the optimal $\varepsilon$ values and the network structure of the MEN.

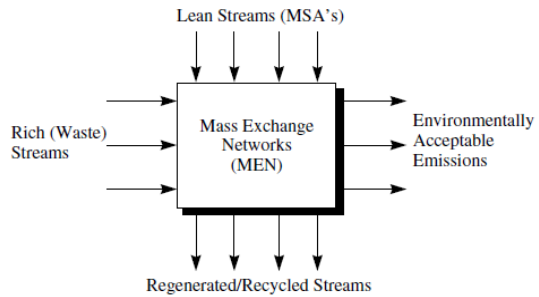

Fig 1: Mass exchange network synthesis [5] 


\section{FUZZY THEORY DETAILS}

The definitions of fuzzy concepts that are relevant for understanding of the fuzzy approach used in this article have been adapted from these sources [6]. These definitions are presented as follows;

\subsection{Definition 1}

A fuzzy set $\tilde{a}$ in a universe of discourse $X$ is characterized by a membership function $\mu_{\tilde{a}}(x)$ that maps each element $x$ in $X$ to a real number in the interval $[0,1]$. The function value $\mu_{\tilde{a}}(x)$ is termed the grade of membership of $x$ in $\tilde{a}$. The nearer the value of $\mu_{\tilde{a}}(x)$ to unity, the higher the grade of membership of $x$ in $\tilde{a}$.

\subsection{Definition 2}

A triangular fuzzy number is represented as a triplet $\tilde{a}=\left(a_{1}\right.$, $\left.a_{2}, a_{3}\right)$. The membership function $\mu_{\tilde{a}}(x)$ of triangular fuzzy number $\tilde{a}$ is given as:

$$
\mu_{\tilde{a}}(x)=\left\{\begin{array}{cc}
\frac{x-a_{1}}{a_{2}-a_{1}}, & x \in\left(a_{1}, a_{2}\right) \\
\frac{a_{3}-x}{a_{3}-a_{2}}, & x \in\left(a_{2}, a_{3}\right) \\
0, & \text { otherwise }
\end{array}\right\}
$$

Where $a_{1}, a_{2}, a_{3}$ are real numbers and $a_{1}, a_{2}, a_{3}$. The value of $x$ at $a_{2}$ gives the maximal grade of $\mu_{\tilde{a}}(x)$, i.e., $\mu_{\tilde{a}}(x)=1$; it is the most probable value of the evaluation data. The value of $\mathrm{x}$ at $\mathrm{a}_{1}$ gives the minimal grade of $\mu_{\tilde{a}}(x)$, i.e., $\mu_{\tilde{a}}(x)=0$; it is the least probable value of the evaluation data. Constants $a_{1}$ and $\mathrm{a}_{3}$ are the lower and upper bounds of the available area for the evaluation data. These constants reflect the fuzziness of the evaluation data. The narrower the interval $\left[a_{1}, a_{3}\right]$, the lower the fuzziness of the evaluation data.

Most decision-making problems have multiple objectives which cannot be optimized simultaneously due to the inherent incommensurability and conflict between these objectives. These problems can be concisely expressed in matrix format as equation (2) where $A_{l}, A_{2}, \ldots, A_{m}$ are possible alternatives among which decision makers have to choose, $\mathrm{C}_{1}, C_{2}, \ldots, C_{n}$ are criteria with which alternative performance are measured, $\mathrm{x}_{\mathrm{ij}}$ is the rating of alternative $\mathrm{Ai}$ with respect to criterion $C_{j}$, $w_{j}$ is the weight of criterion $\mathrm{C}_{\mathrm{j}}[1]$.

$$
\begin{aligned}
& \begin{array}{llll}
C_{1} & C_{2} & \cdots & C_{n}
\end{array}
\end{aligned}
$$

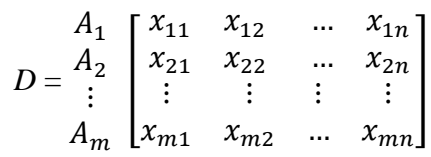

$$
\begin{aligned}
& W=\left[\begin{array}{llll}
w_{1} & w_{2} & \cdots & w_{n}
\end{array}\right]
\end{aligned}
$$

Thus making a tradeoff between these objects becomes a major subject to get the best compromise solution a decision is to be made by evaluating all the related rules at different levels in knowledge base. The evaluations are carried out according to the Max-Min algorithm. Many simple decision processes are based on a single objective, such as minimizing cost, maximizing profit, minimizing run time, and so forth. Often, however decision must be made in an environment where more than one objective is different. It is desired to evaluate how well each alternative, or choice satisfies each objective and to combine the weighted objectives into an overall decision function in some plausible way. This process naturally requires subjective information from the decision authority concerning the importance of each objective. The approach illustrated in this article defines a decision calculus that requires information of the preferences and importance weights, which are minimum $\varepsilon$, amount of mass separating agents (MSA) and the number of exchange units.

Most decision-making problems have multiple objectives which cannot be optimized simultaneously due to the inherent incommensurability and conflict between these objectives. To develop this approach some definitions are required. Define a universe of $n$ alternatives, $A=\left\{a_{1}, a_{2}, \ldots, a_{n}\right\}$, and a set of $r$ objectives, $\mathrm{O}=\left\{\mathrm{O}_{1}, \mathrm{O}_{2}, \ldots, \mathrm{O}_{\mathrm{r}}\right\}$. Let $\mathrm{Oi}$ indicate the ith objective. Then the degree of membership of alternative a in $\mathrm{O}_{\mathrm{i}}$, denoted $\mu \mathrm{O}_{\mathrm{i}}$ (a), is the degree to which alternative a satisfies the criteria specified for this objective. It is desired to seek a decision function that simultaneously satisfies all of the decision objectives; hence, the decision function, $\mathrm{D}$, is given by the intersection of all the objective sets,

$$
D=O_{1} \cap O_{2} \cap \cdots \cap O_{r}
$$

Therefore the grade of membership that the decision function, $\mathrm{D}$, has for each alternative $a$ is given by:

$$
\mu_{D}(a)=\min \left[\mu_{O 1}(a), \mu_{O 2}(a), \ldots \ldots, \mu_{O r}(a)\right]
$$

The optimum decision, $a *$, will then be alternative that satisfies:

$$
\mu_{D}(a *)=\min \left[\mu_{O 1}(a), \mu_{O 2}(a), \ldots \ldots, \mu_{O r}(a)\right]
$$

\section{PROBLEM DESCRIPTION}

As presented in [5] the problem of synthesizing MENs can be stated as follows: Given a number NR of waste (rich) streams (sources) and a number NS of MSAs (lean streams) it is desired to synthesize a cost-effective network of mass exchangers that can preferentially transfer certain undesirable species from the waste streams to the MSAs. Given also are the flow rate of each waste stream, $G_{i}$, its supply (inlet) composition $\mathrm{y}_{\mathrm{i}}$ in, and its target (outlet) composition $\mathrm{y}_{\mathrm{i} \text { out }}(\mathrm{i}=$ $1,2, \ldots, \mathrm{N}_{\mathrm{R}}$ ), where the target composition is mostly imposed by environmental regulations or economical constrains. In addition, the maximal available flow rates for the MSAs, $L_{j}$ $\max \left(j=1,2, \ldots, N_{S}\right)$, and their supply and target compositions, $x_{j}$ in and $x_{j \text { out }}$, are given for each MSA. Equilibrium relation governing the distribution of a transferable component between the $\mathrm{i}$-th rich stream and the $\mathrm{j}$-th lean stream is linear and independent of the presence of other soluble components in the rich stream;

$$
Y_{j}=m_{j} x_{j}+b_{j}
$$

Where both $m_{j}$ and $b_{j}$ are equilibrium constants, whose values depend on the characteristics of the binary system involving the solute and lean stream $\mathrm{j}$. It is necessary to employ the composition differences, $\varepsilon$, to avoid the infinite size of mass exchangers. Therefore, the linear equation that takes $\varepsilon$ into consideration as expressed in Eq. (7)

$$
Y_{j}=m_{j}\left(x_{j}+\varepsilon\right)+b_{j}
$$

In this way, for a given $\mathrm{Y}$, the value of $\mathrm{x}_{\mathrm{j}}$ corresponds to the maximum composition that is practically achievable in the $j$-th lean stream, Similarly, for an $x_{j}$, the value of $Y_{j}$ corresponds to the minimum composition of the pollutant in the $\mathrm{i}$-th rich stream, which is needed to practically transfer the component from rich streams to the MSAs. In most literatures the values of $\varepsilon$ are generally specified as 0.0001 [5] [9]. In this way, the calculating process is simplified, but it is an imprecise approximation. So this article considers $\varepsilon$ as an unequal variable for each pair of streams, employing it to establish an 
optimal fuzzy approach model, trading off capital costs versus operating costs, so as to minimize the TAC.

The objective is to synthesize a network of mass exchange units according to the optimal $\varepsilon$ from a set of assumed ones without the synthesis of the MEN for each assumed $\varepsilon$, which can transfer a set of certain species from the rich streams to the lean streams and that can satisfy the specifications for the rich and lean streams at minimum TAC. With the intention of relaxing the increased computational efforts, a simplified assumption will be utilized in the following proposed synthesis procedure: the mass flow rate of each stream remains essentially unchanged as it passes through the network, because the compositions of the transferable components are usually very low.

\section{SYNTHESIS METHODOLOGY}

In a MEN, the composition of the component in the i-th rich stream decreases, whereas increases in the $\mathrm{j}$-th lean stream. The composition differences are taken as variables, thus the corresponding compositions are represented to be the function of $\varepsilon$. As mentioned before, the minimum allowable composition difference is an optimizable parameter. When $\varepsilon$ is close to zero, infinitely large separators will be required and consequently, the capital cost of the network will be infinite. When $\varepsilon$ increased, the operating cost will increase whereas the fixed cost will decrease. Then a composition interval diagram (CID) can be created; consisting of a series of "composition intervals" which corresponds to the supply or target composition of components for each stream. According to [5] the number of composition intervals can be related to the total number of streams using this expression;

$$
n \leq 2 \times\left(N_{R}+N_{S}\right)-1
$$

Where $\mathrm{N}_{\mathrm{R}}$ and $\mathrm{N}_{\mathrm{S}}$ denote the number of rich and lean streams respectively. The CID employs several composition scales that are in a one-to one correspondence with one another. In the CID, the entire composition range is supposed to be divided into $\mathrm{n}$ composition intervals, with the highest composition interval being denoted as $\mathrm{k}=1$ and the lowest being denoted as the mass exchange load of the i-th rich stream passing through the $\mathrm{k}$-th interval can be calculated using the following expression:

$$
M_{i, K}^{R}=\Sigma G i\left(y_{i, K}-Y_{i, K+1}\right)
$$

Similarly, the mass exchange load of the j-th lean stream passing through the $\mathrm{k}$-th interval is given by:

$$
M_{j, K}^{S}=\Sigma L_{j}\left(x j, K-X_{j, K+1}\right)
$$

Note that, the excess capacity of the process MSAs is the first row in the last column of the CID, and mass load for external MSAs is the last row in the last column.

The total annualized cost (TAC) of a network mainly consists of its operating cost and capital cost. The unit price of each lean stream $\mathrm{j}, \mathrm{C}_{\mathrm{j}}$, is generally known, and suppose the operating cost of a MEN mainly depends on the cost of MSAs used, then the operating cost can be formulated as follows:

$$
\text { Operating cost }=\Sigma_{j} C_{j} L_{j}
$$

Another part of the TAC is the capital cost. The capital cost of plate columns are related to the number of plates and column size, which can be calculated by Kremser's equation.

$$
\begin{array}{cc}
N T P=\frac{\ln \left[\left(1-\frac{1}{A}\right)\left(\frac{Y_{\text {in }}-m_{j} X_{\text {in }}-b_{j}}{Y_{\text {out }}-m_{j} X_{\text {in }}-b_{j}}\right)+\frac{1}{A}\right]}{\ln (A)} & \text { for } A \neq 1 \\
N T P=\frac{Y_{\text {in }}-Y_{\text {out }}}{Y_{\text {out }}-m_{j} X_{\text {in }}-b_{j}} & \text { for } A=1
\end{array}
$$

where $A$ is the absorption factor $A=L_{j} / m_{j} G_{i}, Y_{i \text { in }}, Y_{i \text { out }}, X_{i, j}$ in denote the inlet and outlet compositions of the corresponding component of the i-th rich stream and the j-th lean stream passing through the mass exchanger. Then this type of capital cost can be expressed as follows;

$$
\text { Capital Cost }=\Sigma_{i} \Sigma_{j} C_{i, j}^{\prime} \times N_{i, j}
$$

Where $C_{i, j}^{\prime}$ is the annual cost of each column plate and its value depends on the mass exchanger's type and size.

\section{CASE STUDY AND DISCUSSION \\ 5.1 Sweetening of Coke-Oven Gas [5]}

This problem involves the simultaneous removal of Hydrogen

\begin{tabular}{|c|c|c|c|c|c|c|}
\hline \multicolumn{4}{|c|}{ Rich stream } & & & \\
\hline Stream & $\mathbf{G}_{\mathbf{i}}(\mathrm{Kg} / \mathrm{sec})$ & $\mathbf{Y}_{i}^{\text {in }}{ }_{i}$ & $\mathbf{Y}^{\text {out }}{ }_{i}$ & & & \\
\hline $\mathrm{R}_{1}$ & 0.9 & 0.07 & 0.0003 & & & \\
\hline $\mathrm{R}_{2}$ & 0.1 & 0.051 & 0.0001 & & & \\
\hline \multicolumn{7}{|c|}{ Lean stream } \\
\hline Stream & $\mathbf{L}_{\mathbf{j}}(\mathbf{K g} / \mathbf{s e c})$ & $\mathbf{X}^{\mathrm{in}}{ }_{j}$ & $\mathbf{X}^{\text {out }}{ }_{j}$ & $\mathbf{m}_{\mathbf{j}}$ & $\mathbf{b}_{\mathbf{j}}$ & C (\$.sec/kg.yr) \\
\hline $\mathrm{S}_{1}$ & 2.3 & 0.0006 & 0.0310 & 1.45 & 0 & 117360 \\
\hline $\mathrm{S}_{2}$ & $\infty$ & 0.0002 & 0.0035 & 0.26 & 0 & 176040 \\
\hline
\end{tabular}
Sulfide from two gas streams; Sour coke oven gas (COG) $\left(\mathrm{R}_{1}\right)$ and Tail Gas $\left(\mathrm{R}_{2}\right)$. Figure (2) represent a schematic diagram for the case study, where two MSAs are available: Ammonia $\left(\mathrm{S}_{1}\right)$, which is a process MSA and Methanol $\left(\mathrm{S}_{2}\right)$, which is an external MSA. Stream data are given in table 1.

Table 1. Data for the Streams of case study (COG) for $\mathrm{H}_{2} \mathrm{~S}$

The equilibrium solubility data for hydrogen sulfide in aqueous ammonia and methanol may be correlated by the following relations, respectively:

$\begin{array}{ll}\text { Aqueous ammonia } & \mathrm{Y}_{1}=1.45 \mathrm{X}_{1} \\ \text { Methanol } & \mathrm{Y}_{2}=0.26 \mathrm{X}_{2}\end{array}$

Where the subscript, $\mathrm{j}=1,2$ corresponds to the aqueous ammonia and chilled methanol, respectively. In this example, only the $\mathrm{H}_{2} \mathrm{~S}$ is the pollutant, that is $\mathrm{N}_{\mathrm{P}}=1$ so the subscript $\mathrm{P}$ has not been designated in this example.

Perforated plate columns are considered for both solvents and the annualized investment cost of such a column is considered $\$ 4552$ Ns yr-1 where Ns is the number of theoretical plates in column.. According to the data in table 1, the corresponding composition relations mentioned above can be employed to obtain the CID as shown in table 3. This diagram allows finding the minimum utilities demand and the location of the pinch point for a given minimum $\varepsilon$. By assuming the composition difference equals to 0.0001 and according to the data in table 1 , the corresponding relations mentioned above can be employed to obtain the CID as shown in table 2 . 


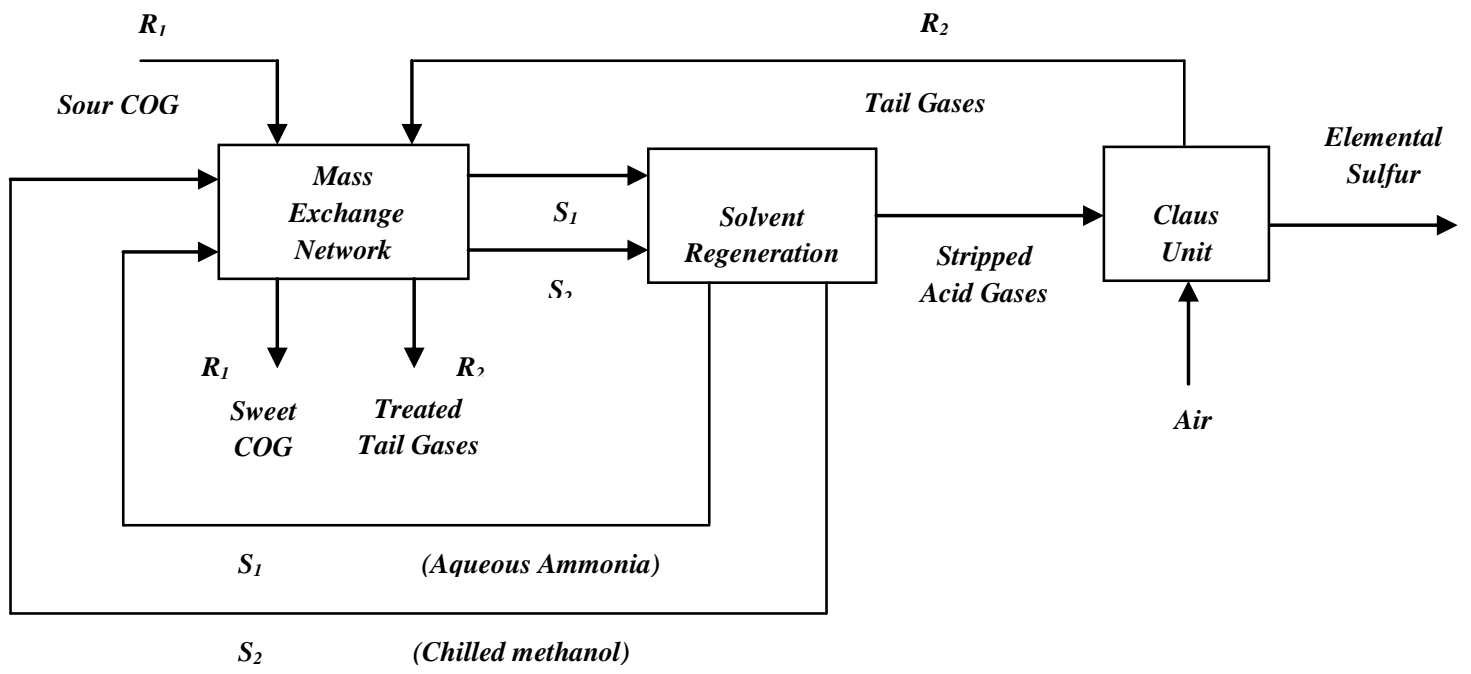

Fig 2: Sweetening of COG [5]

From the CID the following data can be calculated; excess capacity of the aqueous ammonia to remove $\mathrm{H}_{2} \mathrm{~S}=0.00284$ $\mathrm{Kg} / \mathrm{sec}$, actual mass flow rate of aqueous ammonia $\mathrm{S}_{1}=2.3$ $0.00284 /((0.031-0.0006))=2.207 \mathrm{Kg} / \mathrm{sec}$, minimum mass flow rate of $\mathrm{H}_{2} \mathrm{~S}$ to be removed by external MSA $=0.00074$ $\mathrm{Kg} / \mathrm{sec}$ and minimum mass flow rate of chilled methanol required to supplement the separation duty $S_{2}=0.00074 /$ $((0.0035-0.0002))=0.224 \mathrm{Kg} / \mathrm{sec}$. Where the pinch point at the composition of rich stream is 0.00102 and that of the lean stream is 0.0006 .

The next step is to estimate number of theoretical stage (NTS) for each column above and below the pinch by using Kremser's equation [5] as shown in table 3.

$$
N T S=\frac{\ln \left[\left(1-\frac{m G}{L}\right)\left(\frac{y_{i}-m x-b}{y_{o}-m x-b}\right)+\frac{m G}{L}\right.}{\ln \frac{L}{m G}}
$$

There are several objectives to consider before calculating the minimum optimal cost; minimum value of minimum composition approach $(\varepsilon)$, minimum mass flow rate of aqueous ammonia $\left(S_{1}\right)$, minimum mass flow rate of chilled methanol required to supplement the separation duty $\left(S_{2}\right)$ and minimum number of theoretical plates $\left(\mathrm{S}_{3}\right)$

By repeating the previous steps with different values of a minimum composition approach $(\varepsilon)$ and estimate total NTP, $S_{1}$ and $S_{2}$ for each one, as shown in table 4 . The total NTP, S1 and $\mathrm{S}_{2}$ are the criteria affecting the operating cost.

Table 2. Composition interval diagram (CID) at $\varepsilon=0.0001$ for case study (1)

\begin{tabular}{|c|c|c|c|c|c|c|c|c|c|c|c|}
\hline & \multicolumn{5}{|c|}{ Rich streams } & \multicolumn{3}{|c|}{ Lean streams } & & \multicolumn{2}{|c|}{ Cascade Diagram } \\
\hline Interval & \multicolumn{2}{|l|}{$\mathbf{Y}_{\mathbf{i}}$} & \multicolumn{2}{|c|}{$\begin{array}{c}\mathbf{R}_{1} \\
(\mathrm{~kg} / \mathrm{s})\end{array}$} & $\begin{array}{c}\mathbf{R}_{2} \\
(\mathrm{~kg} / \mathrm{s})\end{array}$ & \multicolumn{2}{|c|}{$\mathbf{X}_{\mathbf{j}}$} & $\begin{array}{c}S_{1} \\
(\mathrm{~kg} / \mathrm{s})\end{array}$ & $\Delta \mathbf{m}$ & $\begin{array}{c}\text { Cumulative } \\
\text { Mass } \\
\text { Available }\end{array}$ & $\begin{array}{c}\text { Modified } \\
\text { Cumulative } \\
\text { Mass } \\
\text { Available }\end{array}$ \\
\hline \multirow[t]{2}{*}{0} & 0.0700 & & 0.9 & & & 0.0482 & & & & 0.00000 & 0.00284 \\
\hline & & 0.9 & & & & & & & 0.0171 & & \\
\hline \multirow[t]{2}{*}{1} & 0.0510 & 0.9 & & & 0.1 & 0.0351 & & & & 0.01710 & 0.01994 \\
\hline & & 0.9 & & 0.1 & & & & & 0.005905 & & \\
\hline \multirow[t]{2}{*}{2} & 0.0451 & 0.9 & & 0.1 & & 0.0310 & & $\uparrow$ & & 0.02301 & 0.02584 \\
\hline & & 0.9 & & 0.1 & & & 2.3 & & -0.0258 & & \\
\hline \multirow[t]{2}{*}{3} & 0.00102 & 0.9 & & 0.1 & & 0.0006 & 2.3 & 2.3 & & -0.00283 & 0.00000 \\
\hline & & 0.9 & & 0.1 & & & & & 0.000715 & & \\
\hline \multirow[t]{2}{*}{4} & 0.0003 & 0.9 & $\nabla$ & 0.1 & & 0.0001 & & & & -0.00212 & 0.00072 \\
\hline & & & & 0.1 & & & & & 0.00002 & & \\
\hline 5 & 0.0001 & & & 0.1 & $\mathbf{v}$ & 0.0000 & & & & -0.00210 & 0.00074 \\
\hline
\end{tabular}


Table 3. Values of number of stage for each column above and below the pinch at $\varepsilon=\mathbf{0 . 0 0 0 1}$

\begin{tabular}{|c|c|c|c|c|c|c|}
\hline Column & $\mathbf{1}$ & $\mathbf{2}$ & $\mathbf{3}$ & $\mathbf{4}$ & $\mathbf{5}$ & $\mathbf{N T P}$ \\
\hline NTP & 1 & 12 & 12 & 6 & 2 & 33 \\
\hline
\end{tabular}

Table 4. $S_{1}, S_{2}$ and $S_{3}$ with different $\varepsilon$ values (case study: 1 )

\begin{tabular}{|c|c|c|c|}
\hline $\boldsymbol{\varepsilon}$ & $\begin{array}{c}\mathbf{S}_{\mathbf{1}} \\
(\mathbf{k g} / \mathbf{s e c})\end{array}$ & $\begin{array}{c}\mathbf{S}_{\mathbf{2}} \\
(\mathbf{k g} / \mathbf{s e c})\end{array}$ & $\begin{array}{c}\mathbf{S}_{\mathbf{3}} \\
\text { (Plates) }\end{array}$ \\
\hline 0.00040 & 2.192 & 0.355 & 25 \\
\hline 0.00035 & 2.195 & 0.333 & 25 \\
\hline 0.00030 & 2.196 & 0.312 & 25 \\
\hline 0.00025 & 2.199 & 0.288 & 25 \\
\hline 0.00020 & 2.202 & 0.267 & 28 \\
\hline 0.00015 & 2.204 & 0.245 & 30 \\
\hline 0.00010 & 2.207 & 0.224 & 33 \\
\hline
\end{tabular}

From equations 4 and 5, the values of grades of membership for each criterion can be calculated as follow using the mathematical relation in equation 16.

$\mu=\frac{f-f_{\text {min }}}{f_{\text {max }}-f_{\text {min }}}$

Where:

$f_{\text {max }}=$ the max. value of criteria

$f_{\min }=$ the $\min$. value of criteria

$f=$ the value of criteria

A at optimum value the excess capacity and load to be removed are calculated by using CID of $\varepsilon=0.00025$. The notion of CID at $\varepsilon=0.00025$ can be illustrated in table 6 .
From the CID the following data can be calculated; excess capacity of the aqueous ammonia to remove $\mathrm{H}_{2} \mathrm{~S}=0.00305$ $\mathrm{Kg} / \mathrm{sec}$, actual mass flow rate of aqueous ammonia $\mathrm{S}_{1}=2.3$ $\frac{0.00305}{(0.031-0.0006)}=2.207 \mathrm{Kg} / \mathrm{sec}$, minimum mass flow rate of $\mathrm{H}_{2} \mathrm{~S}$ to be removed by external MSA $=0.00095 \mathrm{Kg} / \mathrm{sec}$ and minimum mass flow rate of chilled methanol required to supplement the separation duty $S_{2}=\frac{0.001095}{(0.0035-0.0002)}=0.224$ $\mathrm{Kg} / \mathrm{sec}$.

Table 5. Calculation of the grade of membership and the optimum decision

\begin{tabular}{|l|l|l|l|l|l|}
\hline $\boldsymbol{\varepsilon}$ & $\mathbf{S}_{\mathbf{1}}$ & $\mathbf{S}_{\mathbf{2}}$ & $\mathbf{S}_{\mathbf{3}}$ & Grade & $\begin{array}{l}\text { Opt. } \\
\text { decision }\end{array}$ \\
\hline 0.00010 & 0.0000 & 1.0000 & 0.0000 & 0.0000 & \\
\hline 0.00015 & 0.1608 & 0.8331 & 0.3750 & 0.1608 & \\
\hline 0.00020 & 0.3287 & 0.6662 & 0.6250 & 0.3287 & \\
\hline $\mathbf{0 . 0 0 0 2 5}$ & $\mathbf{0 . 4 9 6 5}$ & $\mathbf{0 . 5 0 0 0}$ & $\mathbf{1 . 0 0 0 0}$ & $\mathbf{0 . 4 9 6 5}$ & $\mathbf{0 . 4 9 6 5 0 3}$ \\
\hline 0.00030 & 0.6643 & 0.3331 & 1.0000 & 0.3331 & \\
\hline 0.00035 & 0.8322 & 0.1813 & 1.0000 & 0.1813 & \\
\hline 0.00040 & 1.0000 & 0.0000 & 1.0000 & 0.0000 & \\
\hline
\end{tabular}

Where the pinch point at the composition of rich stream is 0.00128 and that of the lean stream is 0.0006 .

The next step is to synthesis mass exchange network at optimum value of $(\varepsilon)=0.00025$ and estimating total annual cost (TAC) of 422570 (\$/year). The optimal network structure is shown in figure (3). In figure (3), numerical value in parenthesis denotes the mass transfer load at the exchange unit, and other values denote composition and / or flow rates. The flow rates of $S_{1}$ and $S_{2}$ are 2.207 and $0.224 \mathrm{~kg} / \mathrm{sec}$ respectively.

Table 6. Composition interval diagram [CID] at $\varepsilon=\mathbf{0 . 0 0 0 2 5}$

\begin{tabular}{|c|c|c|c|c|c|c|c|c|c|c|c|}
\hline \multirow[b]{2}{*}{ Interval } & \multicolumn{5}{|c|}{ Rich streams } & \multicolumn{3}{|c|}{ Lean streams } & \multirow[b]{2}{*}{$\Delta \mathbf{m}$} & \multicolumn{2}{|c|}{ Cascade Diagram } \\
\hline & $\mathbf{Y}_{\mathbf{i}}$ & & $\begin{array}{c}\mathbf{R}_{1} \\
(\mathrm{~kg} / \mathrm{s})\end{array}$ & & $\begin{array}{c}\mathbf{R}_{2} \\
(\mathrm{~kg} / \mathrm{s})\end{array}$ & $\mathbf{X}_{\mathbf{j}}$ & & $\begin{array}{c}\mathrm{S}_{1} \\
(\mathrm{~kg} / \mathrm{s})\end{array}$ & & $\begin{array}{c}\text { Cumulative } \\
\text { Mass } \\
\text { Available }\end{array}$ & $\begin{array}{c}\text { Modified } \\
\text { Cumulative } \\
\text { Mass } \\
\text { Available }\end{array}$ \\
\hline \multirow[t]{2}{*}{0} & 0.0700 & & 0.9 & & & 0.0480 & & & & 0.00000 & 0.00305 \\
\hline & & 0.9 & & & & & & & 0.0171 & & \\
\hline \multirow[t]{2}{*}{1} & 0.0510 & 0.9 & & & 0.1 & 0.0349 & & & & 0.01710 & 0.02015 \\
\hline & & 0.9 & & 0.1 & & & & & 0.0056875 & & \\
\hline \multirow[t]{2}{*}{2} & 0.0453 & 0.9 & & 0.1 & & 0.0310 & & $\uparrow$ & & 0.02279 & 0.02584 \\
\hline & & 0.9 & & 0.1 & & & 2.3 & & -0.02584 & & \\
\hline \multirow[t]{2}{*}{3} & 0.00123 & 0.9 & & 0.1 & & 0.0006 & 2.3 & 2.3 & & -0.00305 & 0.00000 \\
\hline & & 0.9 & & 0.1 & & & & & 0.0009325 & & \\
\hline \multirow[t]{2}{*}{4} & 0.0003 & 0.9 & $\downarrow$ & 0.1 & & 0.0000 & & & & -0.00212 & 0.00093 \\
\hline & & & & & & & & & 0.00002 & & \\
\hline 5 & 0.0001 & & & & $\downarrow$ & -0.0002 & & & & -0.00210 & 0.00095 \\
\hline
\end{tabular}




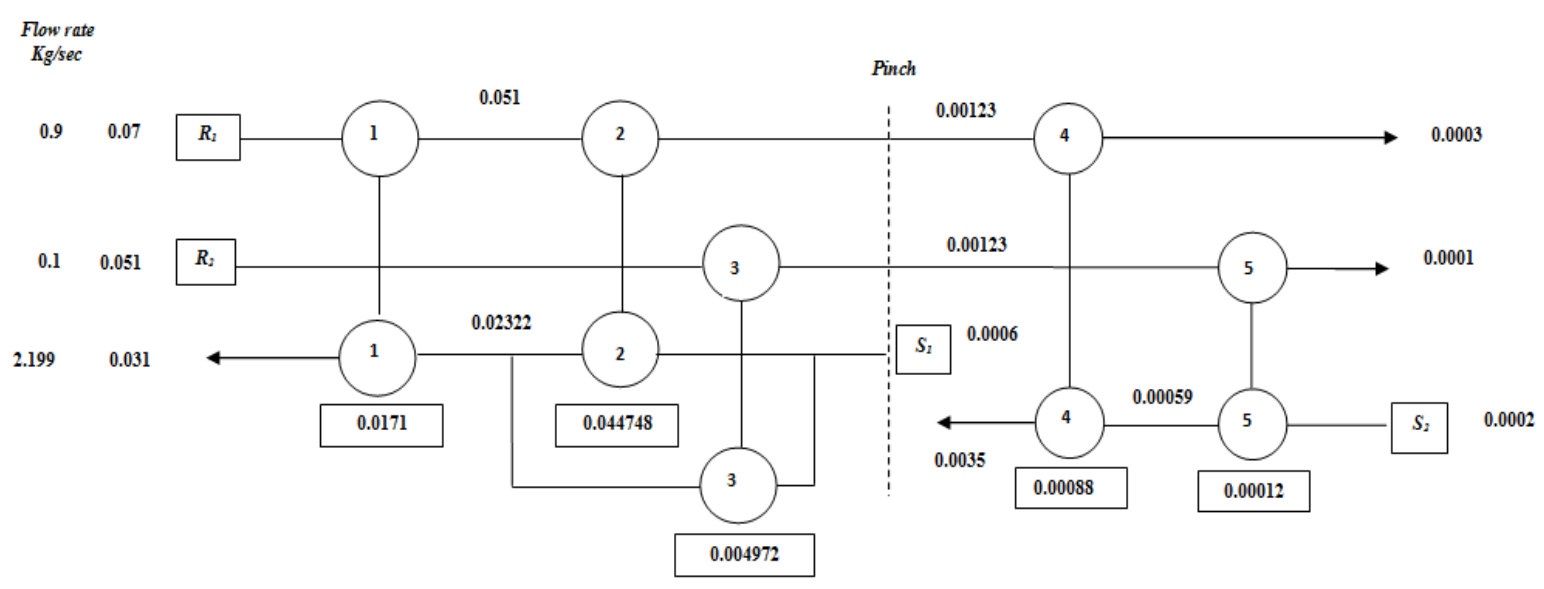

Fig 3: Optimum network design of MEN by using multi-objective decision making at $\varepsilon=0.00025$

\section{CONCLUSION}

It is obvious that the optimization of $\varepsilon$ values is highly important. The fuzzy approach method for structure and the $\varepsilon$ of a MEN is based on the multi objective decision making. The results demonstrate that it is a simplified and convenient way of optimization for the synthesis of a MEN. Through the optimal design of a MEN and the corresponding $\varepsilon$ values, the consequent network is more cost-effective and easier to be determined than other methods, as it considers $\varepsilon$, the operating cost, and the capital cost simultaneously. By comparison the final results of other methods and the proposed method in this article are shown in table (7). According to the reduction present in the total cost, the approach introduced by this article is more convenient than the other methods and demonstrates that it is important to consider a wide range of a minimum composition differences before design rather than using arbitrarily fixed ones. What makes fuzzy approach technique better that other procedures used is that it doesn't require any mathematical background and saves time as it doesn't require calculating the TAC for every $\varepsilon$ assumed. Table (7) represent a comparison between present work and several research techniques used to calculate the minimum total annual cost for the same case study used in this research paper. Table (7) shows that the minimum TAC is obtained by changing the minimum composition approach $(\varepsilon)$ using the fuzzy approach as presented earlier. Figure (4) represent a schematic diagram for the fuzzy approach process procedures used in this research paper.

Table 7. Summary and comparison of total annual costs

\begin{tabular}{|c|c|c|c|c|c|c|}
\hline Author & Process used & $\begin{array}{c}\text { Minimum } \\
\text { composition } \\
\text { approach }(\varepsilon)\end{array}$ & $\begin{array}{c}\text { Number of } \\
\text { actual } \\
\text { stages }\end{array}$ & $\begin{array}{l}\text { Annual fixed } \\
\text { cost (\$/year) }\end{array}$ & $\begin{array}{c}\text { Annual } \\
\text { operating } \\
\text { cost } * 10^{4} \\
(\$ / \text { year })\end{array}$ & $\begin{array}{c}\text { Total annual } \\
\text { cost } * 10^{4} \\
(\$ / \text { year })\end{array}$ \\
\hline $\begin{array}{l}\text { Mahmoud M. El-Halwagi et } \\
\text { al. (1989) [5] }\end{array}$ & $\begin{array}{c}\text { Pinch } \\
\text { Analysis }\end{array}$ & 0.0001 & 50 & 227600 & 29.844 & 52.604 \\
\hline Papalexandri et al. (1994) [9] & $\begin{array}{l}\text { Mixed-integer } \\
\text { nonlinear } \\
\text { programming } \\
\text { (MINLP) }\end{array}$ & 0.0001 & 8 & 37213.2 & 88.079 & 91.800 \\
\hline N. Hallale et al. (2000) [11] & Pinch analysis & 0.0001 & 50 & 227600 & 29.844 & 52.604 \\
\hline N. Hallale et al. (2000) [12] & $\begin{array}{l}\text { Super-target } \\
\text { method }\end{array}$ & 0.00031 & 25 & 113800 & 31.326 & 42.706 \\
\hline Cheng-Liang et al.(2005) & MINLP & 0.0001 & 25 & 113800 & 31.590 & 42.970 \\
\hline Present work & $\begin{array}{c}\text { Fuzzy } \\
\text { Approach }\end{array}$ & 0.00025 & 25 & 113800 & 30.877 & 42.257 \\
\hline
\end{tabular}




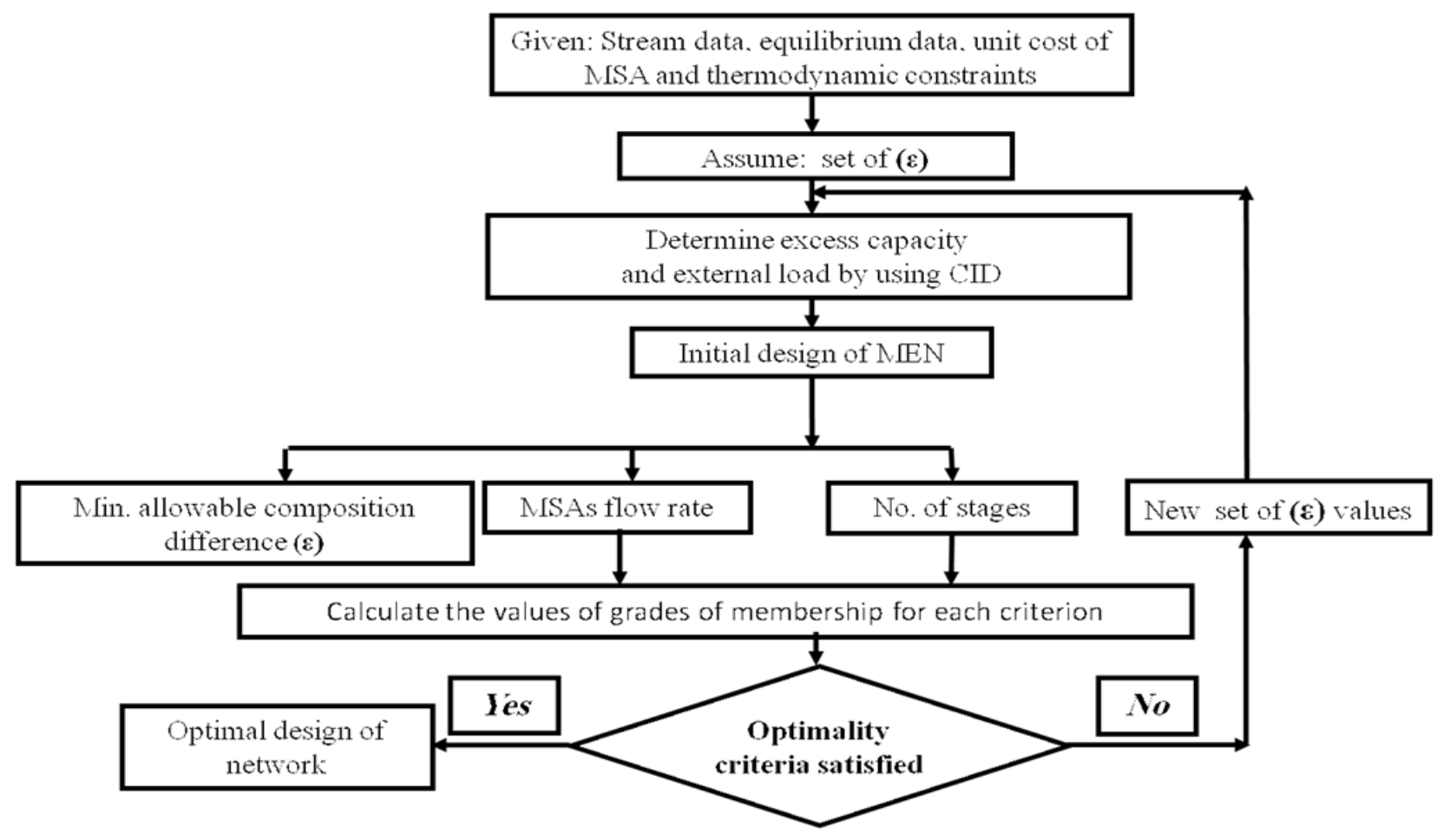

Fig 4: Optimized procedures for MEN in this article

\section{REFERENCES}

[1] Chen, C.-T. (2000). Extension of the TOPSIS for group decision making under fuzzy environment. Fuzzy sets and Systems , 1-9.

[2] El-Halwagi, M. M., \& Manousiouthakis, V. (1990a). Automatic synthethisof mass exchange networks with single component targets. Chem. Eng. Science , 28132831.

[3] El-Halwagi, M. (1999). Pollution Prevention through Mass Integration: Systematic design Tools.

[4] El-Halwagi, M. (1997). Pollution prevention through process integration. San Diego: Academic Press.

[5] El-Halwagi, M., \& Manousiouthakis, V. (1989). Synthesis of Mass Exchange Network. AlChE Journal, 1233-1244.

[6] Fábio J. J. Santos, H. A. (December 2010). Fuzzy Systems for Multicriteria Decision Making. Clei Electronic Jornal, Vol. 13, No. 3, Paper 4.

[7] Fraser, D., \& Shenoy, U. (2004). A new method for sizing mass exchange units without the singularity of thge Kremser equation. Comp. \& Chem. Eng. , 23312335 .

[8] Hallale, N. (2001). Mass transfer technology for pollution prevention. London: M.M. Taylor \& Francis.

[9] M.Wagialla, El-Halwagi, M. M., \& Ponce-Ortega, J. M. (2012). An integrated approach to the optimization of inplant wastewater interception with mass and property constrains. Clean Techn Environ Policy, 257-265.

[10] Papalexandri, K., Pistikopoulos, E., \& Floudas, C. (1994). Mass exchange networks for waste minimization: A simultaneous approach. Trans IChemE , 279-294.

[11] Hallale, N., \& Fraser, D. (2000). Capital and total cost targets for mass exchange networks. Part 1: Simple capital cost models. Computers and Chemical Engineering, $1661-1679$.

[12] Hallale, N., \& Fraser, D. (2000). Supertargeting for Mass Exchange Network, Part I-II. Trans I Chem , 202-2016.

[13] Cheng-Liang Chen \& Ping-Sung Hung (2005). Simultaneous synthesis of mass exchange networks for waste minimization. Elsevier, 1561-1576. 